\title{
A Method of Performance Assessment of PID Controller with Actuator Saturation
}

\author{
Xia Hao \\ Faculty of Electronic and Electrical Engineering \\ Dalian University of Technology \\ Dalian, China \\ E-mail: xifishxi@126.com
}

\author{
Yu Mingli \\ Faculty of Electronic and Electrical Engineering \\ Dalian University of Technology \\ Dalian, China \\ E-mail: yumingli@mail.dlut.edu.cn
}

\begin{abstract}
The purpose of control loop performance assessment is to find a proper method to measure the difference between the actual performance and the predicted performance of the industrial control loop and further identify problems and make adjustments. Therefore, a proper basis to evaluate the correspondingly performance is very important. Actuator saturation is a common phenomenon in the industrial production. In order to establish a performance index accurately, the actuator saturation is need to be taken into account. This paper proposes a method to assess the tracking performance of PID controller under actuator saturation. The optimal controller parameters can be expressed as the function of saturation level based on curve fitting. The lower bound of the step response performance has been established. By comparing with the lower bound through internal model control (IMC) principle regardless of saturation, it can be shown that the proposed method is more reliable. The validity of the new performance index is illustrated by simulations.
\end{abstract}

Keywords-setpoint tracking; internal model control; PID controller; actuator saturation; performance assessment

\section{INTRODUCTION}

The existed performance problems of industrial control loop cause the resources waste and even safety problems. The purpose of control loop performance assessment is to find a proper method to measure the difference between the actual performance and the predicted performance of the industrial control loop and further identify problems and make adjustments. Therefore, a proper basis to evaluate the correspondingly performance is very important [1]. In order to establish a performance index accurately, the phenomenon, e.g. actuator saturation, friction control valves and control valves jumping, is need to be taken into account.

The performance indexes are established to indicate the performance of a control system, and the most common indexes are random performance and deterministic performance indexes. Random performance index reflects the difference between the current control performance and the minimum variance control (MVC). Harris [2] explored the famous minimum variance control and Desborough [3] applied it in univariate feedforward- feedback system. Ko
[4] applied it in cascade control system to solve the problem of random performance evaluation. Deterministic performance assessment method can evaluate the performance of disturbance rejecting or setpoint tracking regardless of the limitation of the controller structure. Swanda [5] found that the adjusting time and integration absolutely error (IAE) can be the index to assess the performance of setpoint tracking. Martin [6] recommended that setting the integration of time and absolute error as the index to evaluate the performance of PID controllers.

There are many existed methods [7] to tune and design the controllers, such as IMC method [8], Ziegler-Nichols method [9], Cohen-Coon method and the direct synthesis method [10]. However, these methods ignored the situation when the actuator saturated. The control loop will have a poor performance when the controller actuator stays in the saturation and open-loop state. Although there are many compensation methods to solve the actuator saturation problem [11], most of them are not easy to analyze the system performance or the controller design is very complicated.

In this paper, a new method is proposed to evaluate the setpoint tracking performance of controller loop with actuator saturation. This paper analyzed the IMC tuning method of PID controllers, established the limitation of the proposed method and found the relationship between the saturation and controller parameters. Compared with the indexes of IMC principle by simulation, the new method is more accurate than IMC method.

\section{INSTRUCTION OF IMC-PID CONTROLLER}

\section{A. IMC Tuning Method of PID Controller}

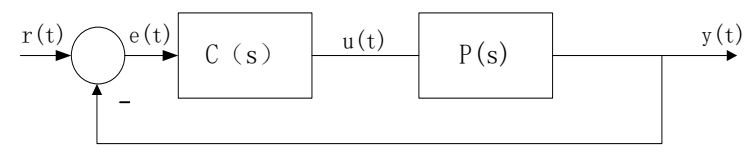

Figure 1. The feedback control loop of SISO

The SISO feedback loop was shown in Fig .1. PID controller $\mathrm{C}(\mathrm{s})$ is :

$$
C(s)=K_{p}\left(1+\frac{1}{T_{i} s}+T_{d} s\right)
$$


The controlled object $\mathrm{P}(\mathrm{s})$ is assumed as stabilization process, and it can be approximated as FOPDT:

$$
P(s)=\frac{K}{T_{1} s+1} e^{-\theta s}
$$

or SOPDT model:

$$
P(s)=\frac{K}{T_{1} s^{2}+T_{2} s+1} e^{-\theta s}
$$

Where $\mathrm{K}, \mathrm{T}$ and $\theta$ represents process gain, time constant and lag time constant.

According to (2) and (3), the parameters of PID controller tuned by IMC principle are expressed in (4)(5):

$$
\begin{gathered}
K_{p}=\frac{T_{1}}{K(\lambda+\theta)}, T_{i}=T_{1}, T_{d}=0 \\
K_{p}=\frac{T_{2}}{K(\lambda+\theta)}, T_{i}=T_{2}, T_{d}=\frac{T_{1}}{T_{2}}
\end{gathered}
$$

Finally, the transfer function of close-loop is:

$$
\begin{aligned}
G_{c l}(s) & =\frac{1}{(\theta+\lambda) s+e^{-\theta s}} e^{-\theta s} \\
& \approx \frac{1}{(\theta+\lambda) s+1-\theta s} e^{-\theta s}=\frac{1}{\lambda s+1} e^{-\theta s}
\end{aligned}
$$

For easy analysis and because the delayed impact on system performance is similar to the impact of positive pole, we defined as $e^{-\theta s} \approx 1-\theta s$ [7], and this will lead to certain errors from the actual system. Referring to the(6), only the parameter $\lambda$ influence the parameter of PID controller and the control performance. Hence, how to find the parameter $\lambda$ is the most important issue during the whole design.

\section{B. The Effect of Saturation for IMC-P/PID Performance}

There are many nonlinear phenomena need to be concerned, this paper focuses on the actuator saturation which leads to the transient value of system response.

The control object is:

$$
P(s)=\frac{1}{20 s+1} e^{-5 s}
$$

The PI controller parameters are $K_{p}=1.2, T_{i}=5$. After IMC tuning, the parameters are $K_{p}=2, T_{i}=20$. The indexes are shown in Tab.I.

TABLE I. DIFFERENT INDEX VALUE WITH AND WITHOUT IMC TUNING

\begin{tabular}{|c|c|c|c|}
\hline \multirow{2}{*}{ Controllers } & \multicolumn{3}{|c|}{ Different Index Value } \\
\cline { 2 - 4 } & $\boldsymbol{I A E}$ & $\boldsymbol{I S E}$ & $\boldsymbol{T V}$ \\
\hline original & $31.05^{\mathrm{a}}$ & 15.32 & 8.71 \\
\hline IMC tuned & 10.86 & 8.43 & 4.12 \\
\hline
\end{tabular}

In this example, the IAE and ISE are all small and indicate the good setpoint tracking performance. If the value of actuator saturation is 1.8 , the control signal and system output are shown in Fig .2.
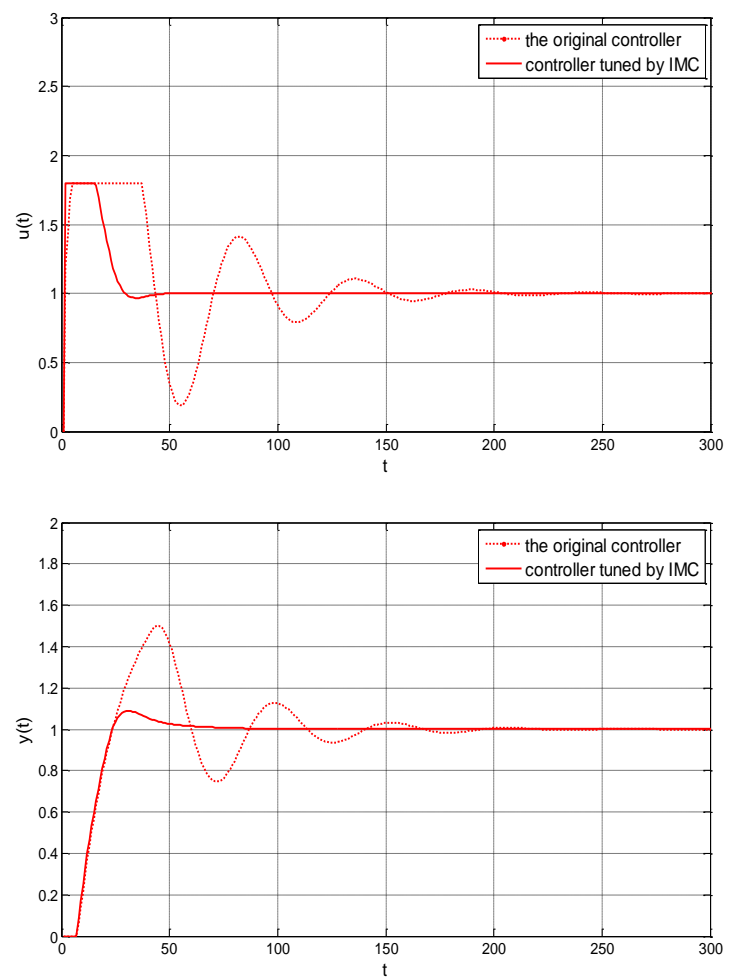

Figure 2. The controller output and system response with actuator saturation $(\operatorname{Umax}=1.8)$

TABLE II. DIFFERENT INDEX VALUE WITH ACTUATOR SATURATION

\begin{tabular}{|c|c|c|c|}
\hline \multirow{2}{*}{ Controllers } & \multicolumn{3}{|c|}{ Different Index Value } \\
\cline { 2 - 4 } & $\boldsymbol{I A E}$ & $\boldsymbol{I S E}$ & $\boldsymbol{T V}$ \\
\hline original & $32.15^{\mathrm{a}}$ & 15.12 & 5.89 \\
\hline IMC tuned & 14.08 & 9.46 & 2.66 \\
\hline
\end{tabular}

It can be seen that the IAE and ISE become bigger and the performance of IMC tuning is effected by the actuator saturation. If we take the optimal index calculated by IMC method without considering the saturation as the standard index, there will be an error for the actual optimal index because the effects of saturation. So it needs to find a method to select the right $\lambda$ to avoid the saturation and choose the tuned control performance as .

\section{THE METHOD OF PID CONTROLLER DESIGNING UNDER SATURATION CONDITION}

\section{A. The method of PID controller designing under saturation condition}

In this paper, several control object models were randomly selected. We selected PI/PID control parameters refer to each different control object model and simulated to obtain control data and recorded the correspondingly maximum output of controller. Finally we found the relationship between parameters of PI/PID controller and the maximum output of controller. Since the optimum integration time can be obtained by IMC tuning method, we got the parameters of $T_{i}$ and $T_{d}$.

As for the FOPDT model, the method of curve fitting as following: 
$S$ is the ratio between the time delay $\theta$ and time constant $\mathrm{T}$, which range from 0.1 to 2 commonly. In this paper, the process gain $\mathrm{K}$ is chosen as $1,2,3,4$ for 4 groups, time delay $\theta$ is chosen as $1,2,3,4$ for 4 groups and the constant $\lambda$ is chosen as $0.2 \mathrm{~T}, 0.4 \mathrm{~T}, 0.6 \mathrm{~T}, 0.8 \mathrm{~T}, \mathrm{~T}$ for 5 groups. After the data was collected, we established the relationship between $\mathrm{K}_{\mathrm{p}}$ and $\mathrm{U}$ by Curve Fitting in Matlab, which was shown in Tab.3. Where $\mathrm{R}^{2}$ represents the degree of curve fitting, squared summation error (SSE), adjusted $\mathrm{R}^{2}$ and the root mean square error (RMSE) reflects the goodness of curve fitting. In Tab. III, the values of adjusted $\mathrm{R}^{2}$ close to 1 , while the SSE and RMSE close to 0 , which showed an accurate fitting result. Here we set two coefficient $\mathrm{A}$ and $\mathrm{B}$ and defined different values of coefficient in the range in Tab. IV :

TABLE III. RELATION COEFFICIENT VALUES

\begin{tabular}{|c|c|c|c|c|c|c|}
\hline \multirow{2}{*}{$\begin{array}{c}\text { coeffici } \\
\text { ent } \\
\text { values }\end{array}$} & $\boldsymbol{A}$ & $\boldsymbol{B}$ & $\boldsymbol{S S E}$ & $\boldsymbol{R}^{\mathbf{2}}$ & $\begin{array}{c}\text { Adj. } \\
\boldsymbol{R 2}\end{array}$ & $\boldsymbol{R M S E}$ \\
\hline 0.6 & 1.60 & 0.012 & 0.025 & 0.998 & 0.998 & 0.017 \\
\hline 0.7 & 1.70 & 0.014 & 0.037 & 0.997 & 0.997 & 0.022 \\
\hline 0.8 & 1.81 & 0.017 & 0.052 & 0.996 & 0.996 & 0.025 \\
\hline 0.9 & 1.92 & 0.018 & 0.065 & 0.995 & 0.995 & 0.028 \\
\hline 1.0 & 2.04 & 0.019 & 0.077 & 0.996 & 0.996 & 0.031 \\
\hline 1.6 & 2.82 & 0.015 & 0.105 & 0.991 & 0.991 & 0.036 \\
\hline 1.7 & 2.97 & 0.014 & 0.097 & 0.992 & 0.992 & 0.035 \\
\hline 1.8 & 3.11 & 0.013 & 0.090 & 0.992 & 0.992 & 0.034 \\
\hline 1.9 & 3.25 & 0.012 & 0.084 & 0.993 & 0.993 & 0.032 \\
\hline 2.0 & 3.40 & 0.012 & 0.079 & 0.993 & 0.993 & 0.031 \\
\hline
\end{tabular}

TABLE IV. COEFFICIENT VALUES OF A AND B UNDER THE DIFFERENT RANGE OF $S$

\begin{tabular}{|c|c|c|}
\hline \multirow{2}{*}{$\begin{array}{c}\text { Coefficient } \\
\text { values }\end{array}$} & \multicolumn{2}{|c|}{ Different Range of S } \\
\cline { 2 - 3 } & $\mathbf{0 . 1 - 1 . 0}$ & $\mathbf{1 . 1 - 2 . 0}$ \\
\hline $\mathrm{A}$ & $1.038 \mathrm{~S}+0.9865$ & $1.376 \mathrm{~S}+0.6374$ \\
\hline $\mathrm{R}^{2}$ & 0.9992 & 0.9996 \\
\hline $\mathrm{B}$ & $0.0223 \mathrm{~S}-0.0018$ & $-0.008 \mathrm{~S}+0.0278$ \\
\hline $\mathrm{R}^{2}$ & 0.9871 & 0.9896 \\
\hline
\end{tabular}

According to the $\mathrm{S}$, the parameter of controller in saturation condition was finally calculated. As for $0.1<\mathrm{S}<1.0$, the parameters were shown as follows.

$$
\left\{\begin{array}{l}
K_{p}=\left(U_{\max }-B\right) / A \\
A=1.0380 S+0.9865 \\
B=0.0223 S-0.0018
\end{array}\right.
$$

When $1.1<\mathrm{S}<2.0$

$$
\left\{\begin{array}{l}
K_{p}=\left(U_{\max }-B\right) / A \\
A=1.376 S+0.6374 \\
B=-0.0080 S+0.0278
\end{array}\right.
$$

As for the SOPDT model, $\mathrm{S}$ is the ratio between the time delay $\theta$ and time constant $T_{2}$, whose common value range from 0.1 to $2 . \mathrm{V}$ is the ratio between $T_{1}$ and $T_{2}^{2}, \mathrm{R}$ equals to $\mathrm{V} / \mathrm{S}$. The process gain $\mathrm{K}$, time delay $\theta$ were chosen as 1, 2, 3,4 for 4 groups. After the data was collected, we established the relationship between $\mathrm{S}$ and $\mathrm{U}$ by Curve Fitting in Matlab, which was shown in Tab.V. The expression coefficient was shown in Tab.VI.

$$
U_{\text {max }}=A K_{P}+B
$$

\begin{tabular}{|c|c|c|c|c|c|c|}
\hline \multirow{2}{*}{$\begin{array}{c}\text { coeffici } \\
\text { ent } \\
\text { values }\end{array}$} & \multicolumn{6}{|c|}{ Different Value } \\
\hline & $A$ & $\boldsymbol{B}$ & $S S E$ & $R^{2}$ & $\begin{array}{c}\text { Adj. } \\
\text { R2 }\end{array}$ & $R M S E$ \\
\hline 0.33 & 1.664 & -0.0004 & 0.00 & 1.00 & 0.998 & 0.017 \\
\hline 0.27 & 1.786 & -0.0001 & 0.00 & 0.99 & 0.999 & 0.002 \\
\hline 0.23 & 1.915 & 0.0182 & 0.00 & 1.00 & 1.000 & 0.000 \\
\hline 0.19 & 2.077 & 0.0194 & 0.00 & 1.00 & 1.000 & 0.000 \\
\hline 0.16 & 2.249 & 0.0140 & 0.00 & 1.00 & 1.000 & 0.001 \\
\hline 0.14 & 2.424 & 0.0001 & 0.00 & 1.00 & 1.000 & 0.000 \\
\hline 0.12 & 2.611 & 0.0069 & 0.00 & 1.00 & 1.000 & 0.000 \\
\hline 0.10 & 2.804 & 0.0440 & 0.03 & 0.99 & 0.989 & 0.038 \\
\hline 0.09 & 3.000 & -0.0147 & 0.00 & 1.00 & 1.000 & 0.000 \\
\hline 0.07 & 3.199 & 0.0464 & 0.00 & 1.00 & 1.000 & 0.000 \\
\hline
\end{tabular}

TABLE V. COEFFICIENT VALUES OF A AND B UNDER THE DIFFERENT RANGE OF $S$

TABLE VI. EXPRESSION COEFFICIENT

\begin{tabular}{|c|c|}
\hline Coefficient values & Values \\
\hline $\mathrm{A}$ & $0.2075 \mathrm{R}+1.812 \mathrm{~S}+0.4859$ \\
\hline $\mathrm{R}^{2}$ & $0.09325,0.995,0.9944,0.07406$ \\
\hline $\mathrm{B}$ & $-0.00505 \mathrm{R}-0.00062 \mathrm{~S}+0.00869$ \\
\hline $\mathrm{R}^{2}$ & $0.007159,0.01885,-0.09658,0.02052$ \\
\hline
\end{tabular}

In this method, the coefficient was defined by the saturation degree of the controller output. The calculated coefficient was influenced by process gain, time constant and time delay. In this paper, the new method was proposed on the basis of the IMC method, so we can design the controller by IMC tuning method directly when it is under unsaturated condition.

\section{B. The Lower Bound of PID Controller Performance under Saturation}

The obtained system closed-loop transfer function from Fig .1 was shown as follow.

$$
\begin{aligned}
G_{c l}(s) & =\frac{K K_{p}}{T s+K K_{P} e^{-\theta s}} e^{-\theta s} \\
& =\frac{K K_{p}}{T s+K K_{P}(1-\theta s)} e^{-\theta s} \\
& =\frac{K K_{p}}{\left(T-K K_{P} \theta\right) s+K K_{P}} e^{-\theta s}
\end{aligned}
$$


Assuming the setting value is a step signal, we finally obtained the response from Fig .1.

$$
\begin{aligned}
Y(s) & =G_{c l}(s) R(s) \\
& =\frac{K K_{p}}{s\left[\left(T-K K_{P} \theta\right) s+K K_{P}\right]} e^{-\theta s}
\end{aligned}
$$

Transformed by Laplace:

$$
y(t)= \begin{cases}0 & , 0 \leq t<\theta \\ 1-e^{-K K_{p}(t-\theta) /\left(T-K K_{p} \theta\right)} & , \theta \leq t<\infty\end{cases}
$$

Deviation signal:

$$
e(t)=r(t)-y(t)= \begin{cases}1, & 0 \leq t<\theta \\ e^{\frac{-K K_{p}(t-\theta)}{T-K K_{p} \theta}}, & \theta \leq t<\infty\end{cases}
$$

The indexes of PID controller performance:

$$
\begin{aligned}
I A E_{0} & =\int_{0}^{\infty}|e(t)| d t=\int_{0}^{\theta} d t+\int_{\theta}^{\infty} e^{\frac{-K K_{p}(t-\theta)}{T-K K_{p} \theta}} d t \\
& =T / K K_{p} \\
I S E_{0} & =\int_{0}^{\infty} e^{2}(t) d t=\int_{0}^{\theta} d t+\int_{\theta}^{\infty} e^{\frac{-2 K K_{p}(t-\theta)}{T-K K_{p} \theta}} d t \\
& =0.5\left(\theta+T / K K_{p}\right)
\end{aligned}
$$

\section{SIMULATION}

In this section, we discuss the influence of saturation phenomenon on system and the effectiveness of the proposed method of PID controller assessment in saturation situation. Meanwhile, the results were compared with IMC tuning method.

Simulation 1: The parameters of PI controller in mixture process are $K_{p}=1.2$ and $T_{i}=6.6$. Identified FOPDT model is shown as follow:

$$
P(s)=\frac{1.088}{20.065 s+1} e^{-5.66 s}
$$

The saturation degree in this system was set as 1.3 , and the controller parameters were $K_{p}=1.01$ and $T_{i}=20.06$, which obtained by the method in this paper. The controller output and the system response was shown in Fig .3. The different index value with actuator saturation was shown in Tab.V.

Table VII. DIFFERENT INDEX VALUE WITH ACTUATOR SATURATION

\begin{tabular}{|c|c|c|c|}
\hline \multirow{2}{*}{ Controllers } & \multicolumn{3}{|c|}{ Different Index Value } \\
\cline { 2 - 4 } & $\boldsymbol{I A E}$ & $\boldsymbol{I S E}$ & $\boldsymbol{T V}$ \\
\hline Prime system & 31.59 & 15.18 & 3.03 \\
\hline IMC & 19.75 & 11.99 & 1.71 \\
\hline Method in this paper & 18.20 & 12.50 & 1.68 \\
\hline Theoretical value & 18.10 & 11.93 & - \\
\hline
\end{tabular}
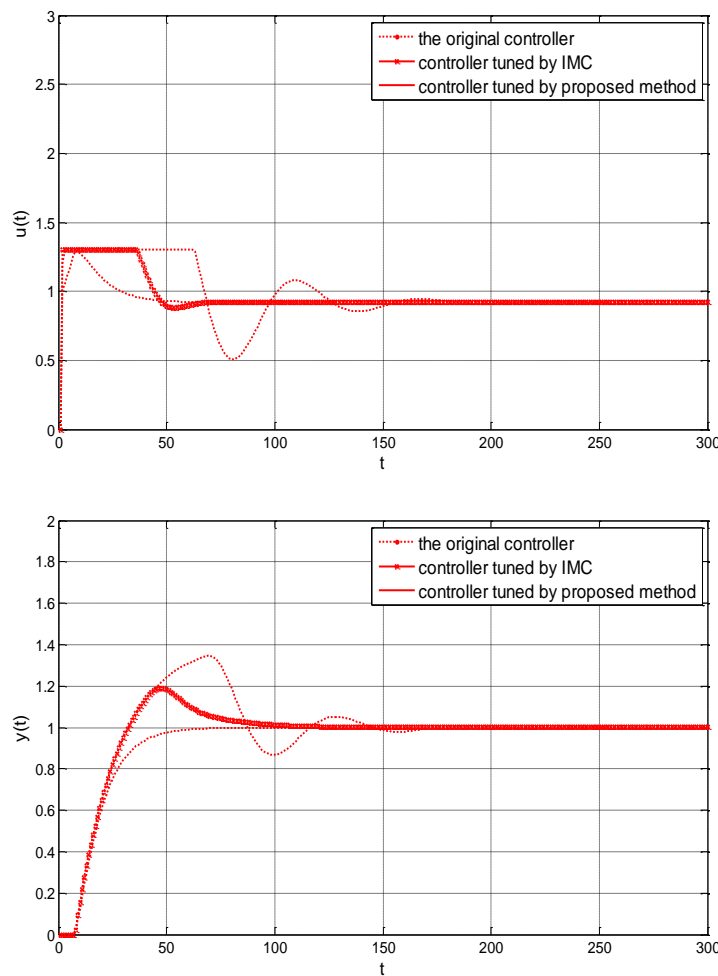

Figure 3. The controller output and system response with actuator saturation is 1.3

Simulation 2: The parameters of PID controller in mixture process are $K_{p}=0.51, T_{i}=3.20$ and $T_{d}=1.08$. Identified FOPDT model is shown as follow:

$$
P(s)=\frac{1.088}{2.045 s^{2}+4.06 s+1} e^{-5.42 s}
$$

The saturation degree in this system was set as 0.95 , and the controller output and the system response was shown in Fig .4. The different index value with actuator saturation was shown in Tab.VIII.

Table VIII. DIFFERENT INDEX VALUE WITH ACTUATOR SATURATION

\begin{tabular}{|c|c|c|c|}
\hline \multirow{2}{*}{ Controllers } & \multicolumn{3}{|c|}{ Different Index Value } \\
\cline { 2 - 4 } & $\boldsymbol{I A E}$ & $\boldsymbol{I S E}$ & $\boldsymbol{T V}$ \\
\hline Prime system & 13.97 & 8.31 & 0.52 \\
\hline IMC & 12.07 & 9.39 & 0.64 \\
\hline Method in this paper & 12.39 & 9.76 & 0.67 \\
\hline Theoretical value & 9.60 & 5.80 & - \\
\hline
\end{tabular}



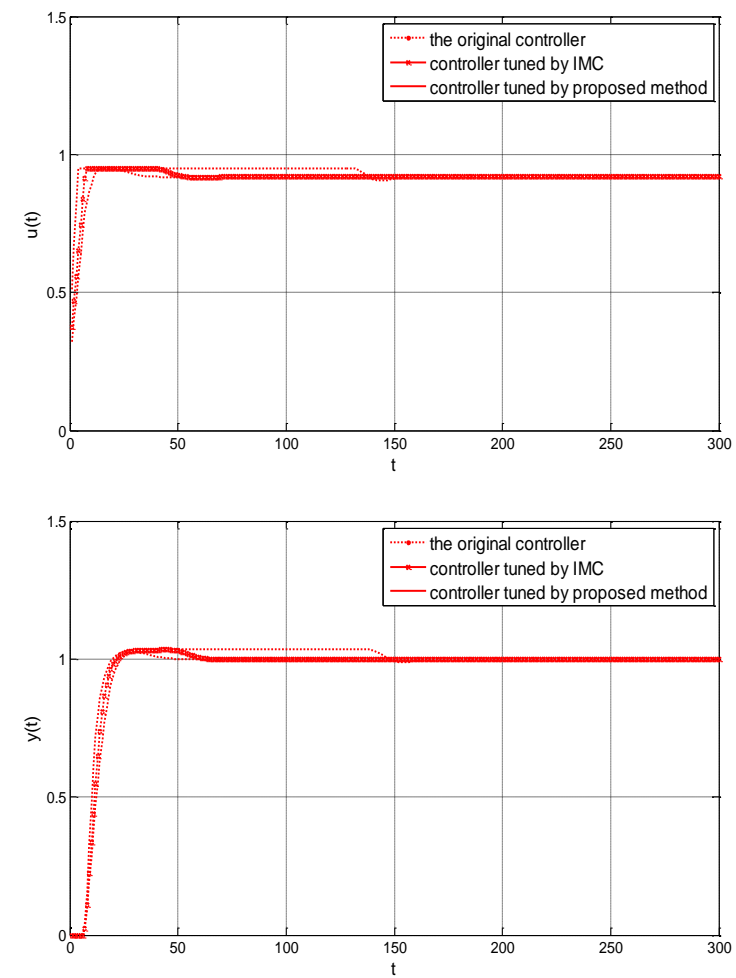

Figure 4. The controller output and system response with actuator saturation is 0.95

\section{CONCLUSION}

Actuator saturation is a common phenomenon in the industrial production. The correct evaluation control loop performance in saturation situation can avoid the miscalculated losses effectively. For the FOPDT model and SOPDT model, we proposed a new controller design method in saturation situation and established the lower bound of performance indexes. Finally we found the new method was more accurate to evaluate the performance of controller loop than the IMC method regardless of the saturation.

\section{ACKNOWLEDGMENT}

The authors would like to express appreciation for the financial support by the National Natural Science Foundation of China (61273098).

\section{REFERENCE}

[1] Z. Yu, J. Wang, B. Huang, Z. Bi, "Performance Assessment of PID Control Loops Subject to Setpoint Changes," J of Process Control, vol. 21(8), 2011, pp. 1164-1171, doi 10.1016/j.jprocont.2011.06.012.

[2] T.J. Harris, “Assessment of Control Loop Performance," Can. J. Chem.Engng., vol.67(10), 1989, pp.856-861, doi: $10.1126 /$ science. 1065467

[3] L. Desborough, T.J. Harris, "Performance Assessment Measures for Univariate Feedback Control," The Canadian Journal of Chemieal Engineering, vol. 70, 1992, pp. 1186-1197. doi: $10.1002 /$ cjce.5450700620.

[4] B. Ko and T.F. Edgar, "Performance Assessment of Cascade Control Loops,“AIChE Journal, vol. 46, 2000, pp. 281-291. doi: 10.1002/aic.690460208.

[5] A.P. Swanda, D.E. Seborg, "Controller Performance Assessmen Based on Setpoint Response Data," Proceedings of the American Control Conference. San Diego, American Control Conference, IEEE Press, 1999, pp. 3863-3867, doi: 10.1109/ACC.1999.786240.

[6] F.G. Martins, "Tuning PID Controllers Using the ITAE Criterion,' Int J Eng Educat, vol. 21(3), 2005, pp. 1-7. doi: 0949-149X/91 $\$ 3.00+0.00$

[7] S. Skogestad, "Simple Analytic Rules for Model Reduction and PID Controller Tuning," J. Process Control, vol. 13, 2003, pp. 291 309. doi: 10.1016/S0959-1524(02)00062-8. doi: 10.1016/S09591524(02)00062-8.

[8] D.E. Rivera, M. Morari, S. Skogestad. "Internal Model Control PID Controller Design," Ind. Eng. Chem. Process Des. Dev, vol. 25, 1986, pp. 252-265. doi: 10.1021/i200032a041.

[9] K. Astrom, T. Hagglund, "Revisiting the Ziegler-Nichols Step Response Method for PID Control," Process Control, vol. 14, 2004, pp. 635-650, doi: 10.1016/j.jprocont.2004.01.002

[10] A. Yaman, John H, "Experimental Study of Internal Model Control," Ind. Eng. Chem. Process Des. Dev, vol. 25, 1986, pp. 102-108, doi: 10.1021/i200032a016.

[11] D.E. Seborg, T.F. Edgar, D.A. Mellichamp, "Process Dynamics and Control," Hoboken, Wiley Press, 2004. 